\title{
SALURAN PEMASARAN KAYU PERTUKANGAN JENIS BAMBANG LANANG (Michelia champaca) YANG MENGUNTUNGKAN PETANI DI SUMATERA SELATAN \\ (Favorable $\mathrm{M}$ arketing $\mathrm{C}$ hannel of B ambang Lanang/Michelia champaca for Farmers in South Sumatra)
}

\author{
Sri Lestari, Bondan Winarno, \& Bambang Tejo Premono \\ Balai Penelitian Kehutanan Palembang; Jl. Kol. H. Burlian Km 6,5 Puntikayu Palembang, Indonesia; \\ e-mail:
}

Diterima 7 Januari 2015 direvisi 13 Maret 2015 disetujui 18 Mei 2015

\begin{abstract}
ABST RACT
Thisrearchaimstostudymarketingadtars pattem of markeingdhanndsandmarketingefficienyof banbanglanangwoodin Lahat andEmpat LavangReegnies SathSumatra Provine Data colletion wasconducted thraughintervienvithrespondentsThe respondants weretheadarsinthemarkeingadivities of bambanglanangwood Therespondants werepurposivdysdeted Thedatawas analyzelqualitativedyandquantitativdy. Theresults of rearchshowed that theadtorsinvdvedinmarketingof bambanglanangwood arefarmess dhainsawmen, trades timberdept, sill/ fumitureindustriesandendconsumess Inthestudyareas, fivemarkeingdhannds of banbanglanangwoodarefound Amongthefivepattems of themarkeingdhannd, thequitehighfamer'sshare(40.91\%) ocureelat markelingdannd pattem 1 (farmers- dainsawmen- traders- timber dept- sill/ fumitureindustriesandendconsumers), pattem2 (famers- dhainsawmen- timberdept- sill/ fumitureindustriesandendconsumess) andpattem3(farmes- tradess- timberdeptsill/ fumitureindustriesandendconsume). Themostefficientmarketingdhannd ispatten2. Thefamesneedtobegiveninformationon efficentmarkeingchand whichisfavaurablefor them
\end{abstract}

Kegucros: Bambanglanangwood, markeingdhannd, farmer.

\begin{abstract}
ABSTRAK
Penelitian ini bertujuan untuk mempelajari pelaku pasar, pola saluran pemasaran dan tingkat efisiensi pemasaran kayu bambang lanang di Kabupaten Lahat dan K abupaten Empat Lawang, Provinsi Sumatera Selatan. Pengumpulan data dilakukan melalui teknik wawancara dengan responden. Sebagai responden adalah aktor dalam rantai pemasaran kayu bambang lanang. Responden dipilih secara purposive Data dianalisis secara kualitatif dan kuantitatif. Hasil penelitian menunjukkan bahwa pelaku pasar dalam rantai kegiatan pemasaran kayu pertukangan jenis bambang lanang adalah petani (produsen), penggesek kayu, pengumpul kayu, pemilik depot kayu, industri kusen/ fumiture dan konsumen pengguna. Di lokasi penelitian ini ditemukan lima pola saluran pemasaran kayu bambang lanang. Di antara kelima pola saluran pemasaran tersebut, farme'sshareyang cukup tinggi (40,91\%) terjadi pada saluran pemasaran pola 1 (petani - penggesek kayu - pedagang pengumpul - depot kayu - industri kusen/ fumituredan konsumen akhir), pola 2 (petani - penggesek kayu - depot kayu - industri kusen/ furnituredan konsumen akhir) dan pola 3 (petani - pedagang pengumpul - depot kayu - industri kusen/ fumituredan konsumen akhir). Saluran pemasaran yang paling efisien adalah saluran pemasaran pola 2. Petani perlu diberikan informasi tentang pola saluran pemasaran efisien yang menguntungkan baginya.
\end{abstract}

Kata kunci: Kayu bambang lanang, saluran pemasaran, petani.

\section{PENDAHULUAN}

Kayu pertukangan jenis bambang lanang (Midhila dampaca) sudah dikenal luas oleh masyarakat di Provinsi Sumatera Selatan, khususnya Kabupaten Lahat dan Kabupaten Empat Lawang. Beberapa petani menanam kayu bambang lanang dengan pola monokultur dan sebagian besar dari mereka menanam dengan pola agroforestri, dicampur dengan tanaman lain atau sebagai batas kebun. Jenis tanaman yang dikembangkan dengan pola agroforestri bersamaan dengan bambang lanang adalah tanaman perkebunan seperti kopi, coklat dan karet atau tanaman buah seperti durian. Kayu bambang lanang dikenal masyarakat sebagai jenis kayu pertukangan dengan kualitas cukup baik, 
dimanfaatkan sebagai bahan untuk membangun rumah, bahan baku pembuatan pintu, kusen, jendela dan furnitureseperti lemari pakaian, lemari hias, kursi dan meja. Oleh karena itu permintaan kayu jenis bambang lanang semakin meningkat dan sebagai konsekuensinya har-ganya pun semakin tinggi.

Pemasaran yang mudah merupakan salah satu insentif bagi masyarakat pengembang kayu bambang lanang di Provinsi Sumatera Selatan, titik kemudahan tersebut dimungkinkan karena pada umumnya pembeli (pedagang pengumpul, penggesek, pemilik IPK H atau pemilik depot kayu) akan datang sendiri ke desa-desa untuk membeli kayu. Akan tetapi, besarnya nilai keuntungan yang tidak menentu di tingkat petani merupakan salah satu disinsentif bagi pengembangan kayu bambang lanang. D itambah lagi adanya invasi dari perkebunan kelapa sawit yang menurut pemahaman banyak pihak lebih menguntungkan dari sisi ekonomi, mengakibatkan beberapa petani kayu beralih pada kelapa sawit.

D alam sistem pemasaran kayu bambang lanang, terdapat beberapa lembaga pemasaran kayu yang terlibat, mulai dari produsen (petani kayu) sampai kepada konsumen akhir, sehingga perlu diketahui tingkat efisiensi pemasaran yang terjadi di lapangan. Berbagai penelitian telah dilakukan untuk mengetahui efisiensi pemasaran dari beberapa jenis produk (Andayani, 2005; Mukson \& al., 2005; D ewi, 2006; Hutabarat, 2006; Effendi, 2007; Hanum, 2007; Setiorini, 2008; Rosmawati, 2011; dan Effendi, 2011). Penelitian tersebut masing-masing melakukan analisis terhadap saluran pemasaran yang ada, sehingga akhirnya diketahui saluran pemasaran yang paling efisien dan dinilai paling menguntungkan. Pada umumnya, hasilnya mengungkapkan bahwa semakin pendek dan sederhana, saluran pemasaran akan semakin efisien. Lebih lanjut Agea $\notin a \mathrm{al}$. (2005) dan Islam \&al.(2014) mengungkapkan bahwa untuk membantu petani sebagai produsen kayu perlu dibentuk koperasi atau asosiasi lokal yang independen agar dapat secara signifikan mengurangi keberadaan pedagang perantara yang biasanya lebih mengendalikan harga.

Pada umumnya, dalam sistem pemasaran kayu yang terjadi di masyarakat, petani selaku produsen akan menjual kayunya dalam bentuk pohon berdiri. $\mathrm{Hal}$ ini disebabkan oleh keterbatasan modal yang dimiliki oleh petani karena untuk melakukan pemanenan kayu membutuhkan biaya yang cukup besar.
Akan tetapi, bagi petani yang memiliki cukup modal dan tidak terdesak oleh kebutuhan hidup maka dalam menjual kayunya memiliki pilihan kepada siapa mereka akan menjual, apakah kepada pemilik depot kayu, kepada pengrajin fumiture, atau kepada lembaga pemasaran lainnya. Petani yang bersangkutan juga memiliki pilihan kapan waktu yang tepat untuk menjual kayunya agar memperoleh harga yang lebih menguntungkan petani itu sendiri. Penelitian ini bertujuan untuk mempelajari saluran pemasaran kayu bambang lanang yang terjadi di masyarakat sebagai upaya untuk mengetahui saluran pemasaran yang paling menguntungkan bagi petani produsen kayu bambanglanang.

\section{METODE PENELITIAN}

\section{A. Lokasi dan Waktu}

Penelitian dilaksanakan di dua kabupaten di Provinsi Sumatera Selatan yaitu Kabupaten Lahat dan Kabupaten Empat Lawang. Di kedua kabupaten tersebut, kayu pertukangan jenis bambang lanang banyak dikembangkan, dimanfaatkan dan diperjual-belikan. Waktu penelitian adalah bulan Mei sampai dengan Juli 2012.

\section{B. Pengumpulan Data}

D ata yang digunakan adalah data primer dan sekunder. D ata primer dikumpulkan dengan cara observasi langsung dan wawancara terhadap responden, yang terdiri dari: petani penanam kayu bambang lanang, pengumpul kayu, penggesek kayu, pemilik depot kayu, pemilik industri penggergajian, dan pemilik industri fumiture $\mathrm{D}$ ata primer yang dikumpulkan antara lain: pelaku pemasaran (petani kayu, penggesek kayu, pedagang pengumpul kayu, pemilik depot kayu dan pemilik industri kusen atau fumiture), harga jual, harga beli, pola saluran pemasaran, biaya pemasaran dan keuntungan.

Petani bambang lanang yang menjadi responden dipilih secara sengaja (purposive sampling. Pelaku pemasaran yang menjadi responden selanjutnya dipilih dengan metode snowball sampling Responden penggesek kayu dan pedagang pengumpul dipilih berdasarkan informasi dari petani yang telah menjual kayunya. Selain itu responden pedagang pengumpul juga 
dipilih berdasarkan informasi dari penggesek, responden depot kayu dipilih berdasarkan informasi dari penggesek dan pedagang pengumpul, dan responden industri berdasarkan informasi dari depot kayu. Pada akhirnya jumlah responden dapat mewakili masing-masing aktor yang terlibat dalam saluran pemasaran kayu, yaitu petani 13 responden, penggesek kayu 6 responden, pedagang pengumpul 4 responden, depot kayu 12 responden dan industri 5 responden. D ata sekunder diperoleh dari instansi pembina produksi dan pemasaran kayu bambang lanang dan studi literatur.

\section{Pengolahan dan Analisis D ata}

D ata dianalisis secara deskriptif kualitatif dan kuantitatif. Analisis kualitatif digunakan untuk menggambarkan fungsi-fungsi pemasaran serta pola saluran pemasaran yang terjadi di lapangan. Saluran pemasaran ditelusuri dari tingkat produsen (petani kayu) sampai ke konsumen, sedangkan analisis kuantitatif ditujukan untuk mengkaji efisiensi pemasaran kayu pertukangan jenis bambang lanang yang terjadi di masyarakat, yaitu dengan menghitung margin pemasaran dan farmer's share

Margin pemasaran terdiri dari dua komponen yaitu biaya pemasaran dan keuntungan pemasaran. Margin pemasaran kayu bambang lanang adalah biaya pemasaran kayu bambang lanang ditambah keuntungan pemasarannya. Margin pemasaran dapat dirumuskan dengan menghitung selisih antara harga di tingkat konsumen dengan harga di tingkat produsen (Mukson \& al., 2005). Andayani (2005) mengungkapkan bahwa besarnya margin pemasaran tersebut dapat dirumuskan:

$\mathrm{Mp}=\operatorname{Pr}-\mathrm{Pf}$

\section{Keterangan:}

$\mathrm{Mp}=$ margin pemasaran

$\operatorname{Pr}=$ harga di tingkatpengecer

Pf $=$ harga di ingkat produsen

Menurut Hendarto dan Wibowo (2005), margin rantai pemasaran adalah jumlah margin pada setiap rantai pemasaran, dirumuskan:

$$
\begin{aligned}
& m_{i}=\sum_{i=1}^{n} M_{i} \\
& m_{i}=\sum_{i=1}^{n}\left(P_{i}-P_{i-1}\right)
\end{aligned}
$$

Keterangan:

$\mathrm{M}_{\mathrm{i}}=$ margin padatitik rantai pemasaran ke-i

$\mathrm{P}_{\mathrm{i}}=$ harga penjualan pada titik rantai pemasaran ke-i

$\mathrm{P}_{\mathrm{i}-1}=$ harga penjualan padatitik rantai pemasaran ke $\mathrm{i}-1$

$\mathrm{m}_{\mathrm{i}}=$ total margin rantai pemasaran

Untuk mengetahui besarnya persentase harga di tingkat produsen terhadap harga di tingkat konsumen dilakukan dengan menghitung farmer's share yang dirumuskan dengan formula:

$$
F S=\frac{P p}{P c} x 100 \%
$$

Keterangan:

Fs = Famme'sshare(kontribusi petani)

$\mathrm{Pp}=$ harga di tingkat produsen

$\mathrm{PC}=$ hargayang dibayarkan oleh konsumen akhir

Semakin tinggi nilai persentase farmer's share yang diterima petani maka kegiatan pemasaran yang dila-kukan semakin efisien (Rosmawati, 2011). Famme's share digunakan untuk melihat seberapa besar bagi-an yang diterima oleh petani ketika melakukan ke-giatan pemasaran komoditi kayu. Oleh karena itu fame's share mempunyai hubungan yang negatif de-ngan margin pemasaran, di mana semakin tinggi margin pemasaran maka bagian yang diperoleh pe-tani akan semakin rendah (Setiorini, 2008).

Untuk menghitung efisiensi pemasaran, formulayang digunakan adalah:

$$
\begin{aligned}
& \mathrm{Ep}=\text { Efisiensi pemasaran } \\
& \mathrm{Tb}=\text { Total biaya pemasaran } \\
& \mathrm{Tnp} \quad=\text { Total nilai produk } \\
& \text { Kaidah keputusan: } \\
& 0-33 \% \quad=\text { Efisien } \\
& 34-67 \% \quad=\text { Kurang efisien } \\
& 68-100 \%=\text { Tidak efisien. }
\end{aligned}
$$$$
\text { Keterangan: }
$$$$
E p=\frac{T b}{T n p} \times 100 \%
$$

\section{HASIL DAN PEMBAHASAN}

\section{A. Sistem Pemasaran Kayu Bambang Lanang}

\section{Lembaga saluran pemasaran}

Kegiatan pemasaran kayu bambang lanang mencakup segala aktivitas yang berhubungan dengan pemindahan hak milik dan fisik kayu bambang lanang dari produsen ke konsumen. Kegiatan pemasaran ini melibatkan berbagai pihak, baik perorangan maupun kelompok di mana pihak-pihak tersebut berlaku sebagai produsen, pedagang dan konsumen. Proses pemindahan hak 
milik dan fisik kayu bambang lanang dari produsen ke konsumen dapat terjadi secara sederhana. Akan tetapi tidak jarang proses pemindahan tersebut terjadi secara kompleks, artinya sebelum sampai ke tangan konsumen, banyak aktor atau lembaga yang terlibat di dalamnya yang bertindak sebagai perantara dari produsen ke konsumen. Menurut Hutabarat (2006), Premono dan Lestari (2012), semakin panjang rantai pemasaran maka semakin besar biaya yang dikeluarkan oleh lembaga-lembaga pemasaran untuk melaksanakan fungsi pemasaran sehingga pada akhirnya akan semakin besar pula margin pemasarannya. Lembaga (aktor) pemasaran yang terlibat dalam proses pemasaran kayu bambanglanang meliputi:

\section{a. Petani}

Produsen kayu bambang lanang adalah petani yang membudidayakan kayu bambang lanang di lahan milik. Pada umumnya petani menjual kayu dalam bentuk pohon berdiri pada kisaran umur 12-15 tahun kepada penggesek kayu yang terdapat di desa mereka. Selain itu ada juga yang langsung menjual kepada pengumpul kayu, terutama bila pengumpul kayu ini datang langsung ke kebun-kebun milik petani. Dalam sistem pemasaran kayu bambang lanang, petani selaku produsen hanya bertindak sebagai pricetaker. Mereka tidak memiliki posisi tawar dalam penentuan harga, terlebih lagi apabila petani menjual kayunya dalam kondisi terdesak oleh kebutuhan hidup, misalnya untuk kebutuhan anak sekolah, keluarga sakit atau menikahkan anggota keluarga. Selain itu, besarnya biaya pemanenan, perijinan, penggergajian serta pengangkutan kayu yang harus dikeluarkan, mengakibatkan petani tidak mempunyai banyak pilihan kepada siapa mereka akan menjual kayunya. Petani cenderung menjual kayunya kepada penggesek atau pedagang pengumpul kayu yang datang ke kebun dan cenderung menyetujui hargayang ditawarkan.

\section{b. Penggesek kayu}

Penggesek kayu membeli kayu secara langsung kepada petani di rumah atau di kebun petani. Di lapangan, penggesek terbagi menjadi dua. Pertama, penggesek kayu yang bertindak sebagai pembeli dan pengumpul kayu. Penggesek kayu jenis ini membeli kayu di lahan milik petani dalam bentuk pohon berdiri dan kemudian dipotong-potong menjadi kayu bulat lalu digergaji menjadi balok kayu atau bilah papan. Pengangkutan kayu bulat dari lokasi penebangan ke tepi jalan diupahkan ke pemilik jasa pengangkutan. Kedua, penggesek kayu yang menerima order untuk menggesek (menggergaji) kayu dari pedagang pengumpul. Penggesek jenis ini mendapatkan uang jasa penggesekan dari pedagang pengumpul atau pemilik depot kayu untuk menebang dan mengolah kayu bulat menjadi kayu balok atau papan.

\section{c. Pedagang pengumpul}

Pedagang pengumpul kayu membeli balok dan papan kayu dari penggesek kayu di desa. Pengumpul kayu memiliki modal yang lebih besar sehingga mereka mampu membeli dan menampung sementara kayu dari penggesek. Pengumpul kayu akan memilih harga yang cocok atau harga yang lebih tinggi dalam menjual kayu, karena permintaan kayu cukup banyak sementara ketersediaannya terbatas. Mereka memiliki kerjasama dengan beberapa pemilik depot kayu atau depot kusen/ fumituredan bertindak sebagai pemasok tetap kepada para pemilik depotkayu/ kusen/ fumituretersebut.

Pengumpul kayu pada saat-saat tertentu juga membeli kayu secara langsung kepada petani di rumah atau di kebunnya. Hal ini dilakukan apabila pengumpul ini sudah kehabisan stok kayu dan tidak ada penggesek yang memasok kayu.

\section{d. Depotkayu}

Pemilik depot kayu melakukan pembelian berupa balok dan papan kayu bambang lanang kepada pengumpul kayu. Pemilik depot memiliki ikatan kerjasama dengan para pengumpul kayu. Setiap kali para pemilik depot kehabisan stok kayu, para pengumpul langsung memasok kayu sesuai dengan yang dibutuhkan. Akan tetapi, pada saatsaat tertentu, para pemilik depot kayu juga melakukan pembelian langsung kepada para penggesek kayu di tingkat desa terutama apabila permintaan kayu di depot meningkat dan melebihi stok yang tersedia.

\section{e. Industri kusen/ furniture}

Para pemilik industri kusen atau fumiturelebih menyukai membeli kebutuhan bahan baku kayu bambang lanang berupa balok dan papan dari depot kayu dibandingkan membeli langsung ke penggesek atau pengumpul. Apabila membeli ke depot kayu, pengusaha kusen/furniture bisa memilih bahan baku dengan spesifikasi yang sesuai dengan kebutuhan, sedangkan jika membeli kayu bambang lanang langsung kepada penggesek kayu tingkat desa atau pedagang pengumpul, pemilik industri ini harus membeli secaraborongan. 


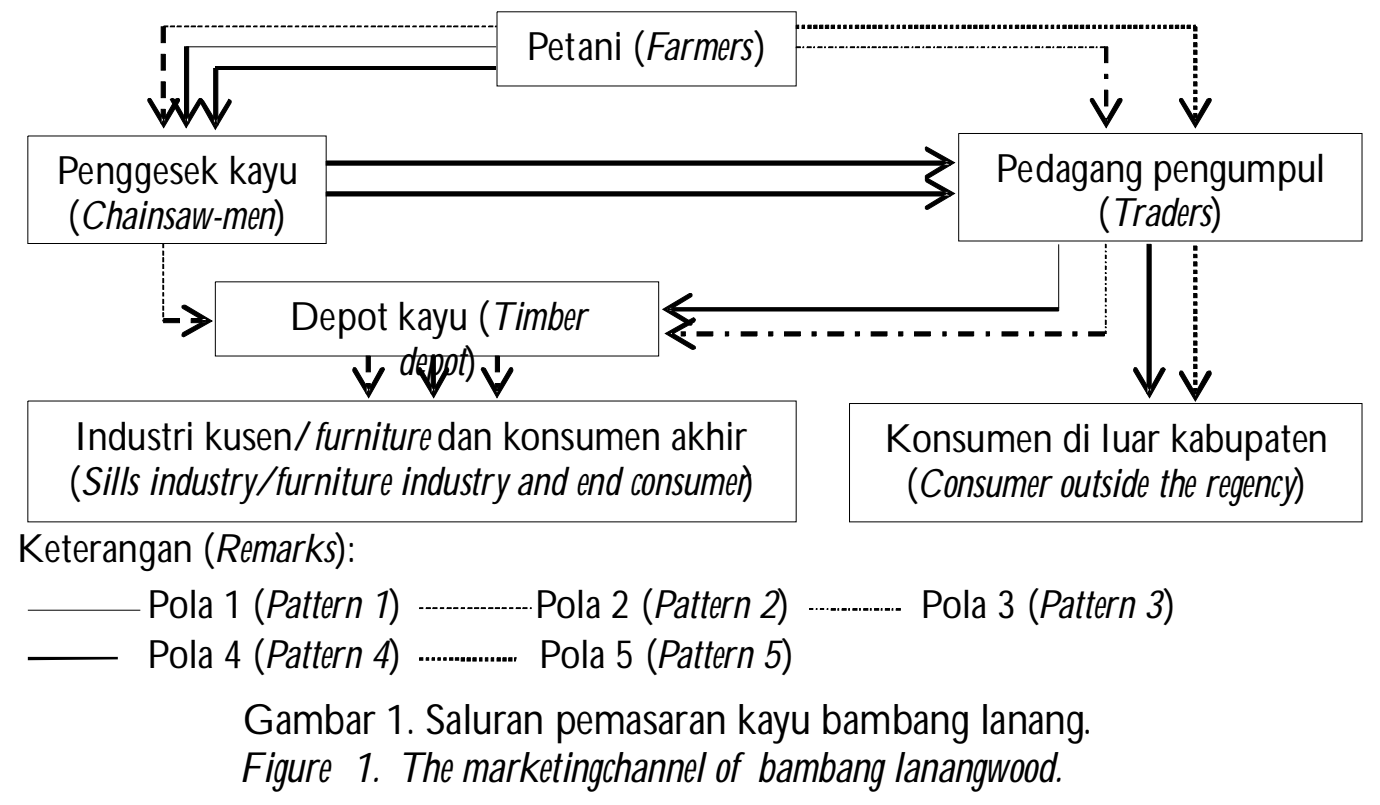

\section{Saluran pemasaran}

Saluran pemasaran kayu bambang lanang di Kabupaten Lahat dan Kabupaten Empat Lawang memiliki lima pola saluran (Gambar1), yaitu:

a. Pola 1: Petani - penggesek kayu - pedagang pengumpul - depot kayu - industri kusen/ fumiture- konsumen akhir

b. Pola 2 : Petani - penggesek kayu - depot kayu industri kusen/ fumiture- konsumen akhir

c. Pola 3 : Petani - pedagang pengumpul - depot kayu - industrikusen/ fumiture- konsumen akhir

d. Pola 4 : Petani - penggesek kayu - pedagang pengumpul - luarkabupaten

e. Pola 5 : Petani - pedagang pengumpul - luar kabupaten.

Petani sebagai produsen kayu menjual pohon berdiri atau tegakan kepada penggesek kayu atau pengumpul kayu tingkat desa. Penggesek kemudian menjual kayu dalam bentuk balok dan papan kepada pedagang pengumpul atau langsung kepada pemilik depot kayu. Pedagang pengumpul selanjutnya menjual balok dan papan kepada pemilik depot kayu atau menjual langsung ke luar kabupaten. Pada akhirnya depot kayu menjual balok dan papan kepada pengusaha kusen/ industri fumituredan konsumen akhir.

Pada saat petani menjual pohon langsung kepada pedagang pengumpul, pedagang pengumpul mengupahkan kepada pihak lain (penggesek kayu) dalam penebangan dan pengolahannya menjadi bilah-bilah papan. Semua biaya ditanggung oleh pedagang pengumpul sehingga harga yang diterima oleh petani merupakan harga bersih.

\section{B. Efisiensi Pemasaran Kayu Bambang Lanang}

\section{Margin pemasaran}

Margin pemasaran terdiri dari biaya pemasaran dan keuntungan dari lembaga pemasaran. Tabel 1 menunjukkan besarnya margin pemasaran dari tingkat penggesek kayu sampai konsumen akhir (masyarakat pengguna dan industri kusen/ fumiture. D ari Tabel 1 dapat dilihat bahwa margin pemasaran tertinggi diperoleh pedagang pengumpul pada pola saluran 5 (petani - pedagang pengumpul - luar kabupaten) meskipun biaya

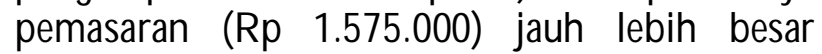
dibandingkan nilai keuntungan ( $R p 225.000)$. Biaya pemasaran yang relatif besar disebabkan oleh tingginya biaya transportasi, mulai dari lokasi tebangan sampai kepada kon-sumen di luar kabupaten.

Petani sebagai pengikut harga dengan posisi tawar yang rendah hanya menerima harga jual $\mathrm{Rp}$ 900.000 per $\mathrm{m}^{3}$. Harga tersebut diterima oleh petani setelah menunggu selama 12-15 tahun sejak mena-nam bibit pohon bambang lanang sampai ditebang.

\section{Keuntungan pemasaran}

Keuntungan pemasaran diperoleh dari besarnya margin pemasaran dikurangi biaya pemasaran yang dikeluarkan oleh masing-masing lembaga pemasaran. Menurut Rosmawati (2011), keuntungan lembaga pemasaran merupakan balas jasa yang diterima oleh masing-masing lembaga 
Tabel 1. Margin pemasaran kayu bambang lanang padamasing-masing saluran pemasaran Table1. Markeingmargin of bambanglanangwoodineachmarkeingdhannd

\begin{tabular}{|c|c|c|c|c|}
\hline No & Saluran pemasaran (Marketingdhannd) & $\begin{array}{l}\text { Harga jual (Seling } \\
\text { price) }\left(\mathrm{Rp} / \mathrm{m}^{3}\right)\end{array}$ & $\begin{array}{l}\text { Harga beli (Purchase } \\
\text { pice) }\left(\mathrm{Rp} / \mathrm{m}^{3}\right)\end{array}$ & $\begin{array}{c}\text { Margin pemasaran } \\
\text { (Marketingmargin) (Rp) }\end{array}$ \\
\hline \multirow[t]{4}{*}{1.} & Petani (Fames) & 900.000 & & \\
\hline & Penggesek kayu (Chainsawłme) & 1.600 .000 & 900.000 & 700.000 \\
\hline & Pedagang pengumpul (Tradas) & 1.900 .000 & 1.600 .000 & 300.000 \\
\hline & D epot kayu (Tinber depot) & 2.200 .000 & 1.900 .000 & 300.000 \\
\hline \multirow[t]{3}{*}{2.} & Petani (Famms) & 900.000 & & \\
\hline & Penggesek kayu (Chainsawłrm) & 1.700 .000 & 900.000 & 800.000 \\
\hline & D epot kayu (Tinber dqpot) & 2.200 .000 & 1.700 .000 & 500.000 \\
\hline \multirow[t]{3}{*}{3.} & Petani (Fames) & 900.000 & & \\
\hline & Pedagang pengumpul (Tradas) & 1.900 .000 & 900.000 & 1.000 .000 \\
\hline & D epot kayu (Tinber depot) & 2.200 .000 & 1.900 .000 & 300.000 \\
\hline \multirow[t]{3}{*}{4.} & Petani (Fames) & 900.000 & & \\
\hline & Penggesek kayu (Chainsawłrm) & 1.600 .000 & 900.000 & 700.000 \\
\hline & Pedagang pengumpul (Trades) & 2.600 .000 & 1.600 .000 & 1.000 .000 \\
\hline \multirow[t]{2}{*}{5.} & Petani (Fames) & 900.000 & & \\
\hline & Pedagang pengumpul (Tradas) & 2.600 .000 & 900.000 & 1.700 .000 \\
\hline
\end{tabular}

Tabel 2. Keuntungan yang diterima oleh masing-masing lembaga pemasaran Table2. Profits reeived by eachmarketingageny

\begin{tabular}{|c|c|c|}
\hline No & Saluran pemasaran (Marketingdharnd) & Keuntungan (benfits) $\left(\mathrm{Rp} / \mathrm{m}^{3}\right)$ \\
\hline \multirow[t]{3}{*}{1.} & Penggesek kayu (Chainsawғmen) & 225.000 \\
\hline & Pedagang pengumpul (Tradas) & 150.000 \\
\hline & D epot kayu (Timber dept) & 150.000 \\
\hline \multirow[t]{2}{*}{2.} & Penggesek kayu (Chainsauसmm) & 225.000 \\
\hline & D epot kayu (Tinber dept) & 350.000 \\
\hline \multirow[t]{2}{*}{3.} & Pedagang pengumpul (Tradas) & 175.000 \\
\hline & D epot kayu (Timber depot) & 150.000 \\
\hline \multirow[t]{2}{*}{4.} & Penggesek kayu (ChainsawFmen) & 225.000 \\
\hline & Pedagang pengumpul (Tradas) & 250.000 \\
\hline 5. & Pedagang pengumpul (Trades) & 225.000 \\
\hline
\end{tabular}

pemasaran yang turut serta memasarkan suatu produk (kayu bambang lanang) mulai dari tingkat petani sampai ke konsumen.

Besarnya keuntungan lembaga pemasaran kayu bambang lanang dapat dilihat pada Tabel 2. D ari Tabel 2 diketahui bahwa nilai keuntungan tertinggi didapatkan oleh pemilik depot kayu pada saluran pemasaran pola 2 (petani - penggesek kayu - depot kayu - industri kusen/ fumiture- konsumen akhir), kemudian disusul oleh pedagang pengumpul pada saluran pemasaran pola 4 (petani - penggesek kayu - pedagang pengumpul - luar kabupaten). Keuntungan penggesek kayu yang relatif besar pada pola pemasaran 1, 2, dan 3 dikarenakan penggesek melakukan kegiatan-kegiatan penebangan, pemotongan batang menjadi kayu bulat, dan menggergaji kayu bulat menjadi balok dan papan. Keuntungan yang relatif besarjuga diperoleh pedagang pengum- pul pada pola pemasaran 4 dan 5 karena mereka melakukan kegiatan-kegiatan yang sama seperti penggesek kayu. Keuntungan besar yang diterima oleh pemilik depot pada pola pemasaran 2 karena depot dapat langsung membeli pada penggesek ka-yu dengan hargayang relatif rendah.

\section{Efisiensi sistem pemasaran}

Efisiensi pemasaran kayu bambang lanang di Kabupaten Lahat dan Empat Lawang disajikan pada Tabel 3. Berdasarkan kriteria efisiensi pemasaran, saluran pemasaran pola 2 merupakan saluran pemasaran yang paling efisien, dengan nilai efisiensi terkecil yaitu 32,95\%, sedangkan saluran pemasaran pola 1, 3, 4 dan 5 termasuk ke dalam kategori kurang efisien. Saluran pemasaran pola 2 mampu mentransfer kayu bambang lanang dari produsen ke konsumen akhir dengan biaya 
Tabel 3. Efisiensi pemasaran kayu bambang lanang pada masing-masing saluran pemasaran Table3. Marketingeficiengy of bambanglanangwoodat eachmarkeingdhannd

\begin{tabular}{|c|c|c|c|c|}
\hline No & Saluran pemasaran (Markeingdhannd) & $\begin{array}{c}\text { Total nilai } \\
\text { produk (Tdal } \\
\text { valueofprodud) } \\
\left(\mathrm{Rp} / \mathrm{m}^{3}\right)\end{array}$ & $\begin{array}{c}\text { Total biaya } \\
\text { pemasaran } \\
\text { (Tdal cost of } \\
\text { markding } \\
\left(\mathrm{Rp} / \mathrm{m}^{3}\right)\end{array}$ & $\begin{array}{l}\text { Efisiensi } \\
\text { pemasaran } \\
\text { (Markeing } \\
\text { fideng) } \\
(\%)\end{array}$ \\
\hline \multirow{5}{*}{1.} & Petani (Fammers) & 900.000 & - & - \\
\hline & Penggesek kayu (Chainsawmmen) & 1.600 .000 & 475.000 & 29,69 \\
\hline & Pedagang pengumpul (Tradas) & 1.900 .000 & 150.000 & 7,89 \\
\hline & Depot kayu (Tinber depot) & 2.200 .000 & 150.000 & 6,82 \\
\hline & Efisiensi saluran pemasaran (Efidengy of markeingdhannd & & & 35,23 \\
\hline \multirow[t]{4}{*}{2.} & Petani (Fames) & 900.000 & & \\
\hline & Penggesek kayu (Chainsawłmen) & 1.700 .000 & 575.000 & 33,82 \\
\hline & Depot kayu (Timber dept) & 2.200 .000 & 150.000 & 6,82 \\
\hline & Efisiensi saluran pemasaran (Eficengy of markeingdhannd & & & 32,95 \\
\hline \multirow[t]{4}{*}{3.} & Petani (Fames) & 900.000 & - & \\
\hline & Pedagang pengumpul (Tradas) & 1.900 .000 & 825.000 & 43,42 \\
\hline & Depot kayu (Tinber dept) & 2.200 .000 & 150.000 & 6,82 \\
\hline & Efisiensi saluran pemasaran (Eficiengy of markeingdhannd & & & 44,32 \\
\hline \multirow[t]{4}{*}{4.} & Petani (Fames) & 900.000 & - & \\
\hline & Penggesek kayu (Chainsaw $m$ me) & 1.600 .000 & 475.000 & 29,69 \\
\hline & Pedagang pengumpul (Trades) & 2.600 .000 & 750.000 & 28,85 \\
\hline & Efisiensi saluran pemasaran (Efidengy of markeingdhamn) & & & 47,12 \\
\hline \multirow[t]{3}{*}{5.} & Petani (Fames) & 900.000 & - & \\
\hline & Pedagang pengumpul (Tradas) & 2.600 .000 & 1.475 .000 & 56,73 \\
\hline & Efisiensi saluran pemasaran (Eficiengy of markeingdhannd & & & 56,73 \\
\hline
\end{tabular}

Tabel 4. Farme'ssharekayu bambang lanang pada masing-masing saluran pemasaran Table4. Fame's share of bambanglanangwoodat each markeingdhannd

\begin{tabular}{cc}
\hline Saluran pemasaran (Marketinghannd) & Farme'sshare $(\%)$ \\
\hline 1 & 40,91 \\
2 & 40,91 \\
3 & 40,91 \\
4 & 34,62 \\
5 & 34,62 \\
\hline
\end{tabular}

minimal dan distribusi pendapatan yang adil dari harga yang dibayar konsumen terhadap semua lembaga tataniaga yang ada.

\section{Farmer'sshare}

Semakin tinggi famm's shareyang diterima oleh petani kayu bambang lanang semakin efisien kegiatan pemasaran yang dilakukan. Besarnya persentase farme's sharedapat digunakan sebagai acuan untuk menentukan efisien atau tidaknya suatu kegiatan pemasaran (tingkat efisiensi pemasaran). Tabel 4 menyajikan fame'ssharemasing-masing saluran pemasaran kayu bambang lanang di dua kabupaten lokasi penelitian. Dari Tabel 4 dapat dilihat bahwa saluran pemasaran pola 1, 2 dan 3 memberikan famm'sshare yang sama sebesar 40,91\% . Famm'ssharedari ketiga pola saluran pemasaran tersebut lebih tinggi dibandingkan dua saluran pemasaran yang lain (saluran pola 4 dan 5) yang hanya sebesar 34,62\%. D engan demikian dapat disimpulkan bahwa saluran pemasaran pola 1, 2 dan 3 lebih efisien dibandingkan saluran pemasaran pola 4 dan 5 .

Tingginya nilai farme's sharepada saluran pola 1, 2 dan 3 dikarenakan saluran pemasaran yang bersifat lokal, yang menyebabkan harga di tingkat konsumen akhir tidak terlalu tinggi karena biaya pemasaran yang relatif lebih rendah. Untuk saluran pola 4 dan 5, karena dijual di luar kabupaten maka harga di tingkat konsumen relatif lebih tinggi, disebabkan oleh tingginya biaya pemasaran. 


\section{KE SIMPULAN DAN SARAN}

\section{A. Kesimpulan}

Pelaku pasar yang terlibat dalam pemasaran kayu pertukangan jenis bambang lanang di Provinsi Sumatera Selatan terdiri dari: petani (produsen), penggesek kayu, pengumpul kayu, pemilik depot kayu, industri kusen/ industri fumiture dan masyarakat pengguna. Pemasaran kayu pertukangan jenis bambang lanang di kabupaten contoh memiliki 5 pola saluran pemasaran:

- Pola 1: petani - penggesek kayu - pedagang pengumpul - depot kayu - industri kusen/ furniture konsumen akhir.

- Pola 2: petani - penggesek kayu - depot kayu industri kusen/ furniture- konsumen akhir.

- Pola 3: petani - pedagang pengumpul - depot kayu - industri kusen/ fumiture - konsumen akhir.

- Pola 4: Petani - penggesek kayu - pedagang pengumpul - luarkabupaten.

- Pola 5: Petani - pedagang pengumpul - luar kabupaten.

Di antara kelima pola saluran pemasaran tersebut, famer'sshareyang cukup tinggi $(40,91 \%)$ diterima petani produsen kayu pada pola 1 (petani penggesek kayu - pedagang pengumpul - depot kayu - industri kusen/ fumiture- konsumen akhir), pola 2 (petani - penggesek kayu - depot kayu industri kusen/ fumiture- konsumen akhir) dan pola 3 (petani - pedagang pengumpul - depot kayu industri kusen/ fumiture- konsumen akhir). Saluran pemasaran yang paling efisien adalah pola 2 (petani - penggesek kayu- depot kayu - industri kusen/ fumiture- konsumen akhir) dengan nilai efisiensi sebesar 32,95\%.

\section{B. Saran}

Pola saluran pemasaran kayu bambang lanang berpengaruh terhadap pendapatan petani, sehingga pemerintah daerah perlu menginformasikan pola saluran pemasaran yang menguntungkan petani. Pemerintah daerah dan dinas kehutanan setempat perlu selalu memperbaharui informasi tentang harga kayu dan pola saluran pemasaran yang menguntungkan bagi peningkatan pendapatan petani.

\section{DAFTAR PUSTAKA}

Agea, J.G., Ssebuliba, E., \& O baa, B. (2005). Marketing of agroforestry production Nama Sub-County, Mukono District, Uganda. AfricanCropsaieneSaidy, 7, 537-540.

Dandayani, W. (2005). Pola distribusi dan tingkat efisiensi tataniaga biji mete (Anacardium ocidataleL) rakyat di Kabupaten Wonogiri. Jumal HutanRakjat,7(2), 11-42.

D ewi, U. (2006). Analisiskedayakan usahatani dan fisiensi pemasaran salak ponddh: kasus di Kecamatan Madukara, Kabupaten Banjamegara, Proinsi Java Tengah (Skripsi). Program Studi Manajemen Agribisnis, Fakultas Pertanian, InstitutPerta-nian Bogor, Bogor.

Effendi, R. (2007). Kajian tata niaga kayu rakyat di Jawa bagian barat. ProsidngPengenbanganHur tan Rakyat Mendukung Kdestarian Produks Kayu Rakyat, Bogor 3 D esember 2007 (pp. 109-127). Bogor: Pusat Penelitian Sosial Ekonomi dan Kebijakan Kehutanan.

Effendi, R. (2011). Kajian tata niaga kayu rakyat di Pulau Jawa bagian barat. Jumal PenditianHu tanTanaman, 8(4), 251-258.

Hanum, F. (2007). Analisis sisempemasaran produk ldsahmadu PT Madu Pramka Cibubur Jakarta Timr. (Skripsi). Program Studi Sosial Ekonomi Peternakan, Fakultas Peternakan, InstitutPertanian Bogor, Bogor.

Hendarto, K.A. \& Wibowo, L.R. (2005). Bagaimana menghitung tataniga (rantai pemasaran) pada hasil hutan bukan kayu. Jumal HutanRakyat, 7(2), 1-9.

Hutabarat, S. (2006). Analisis efisiensi pemasaran karet perkebunan karet rakyat di K abupaten Rokan Hilir. Jumal Ekanom Penbangunan, 14(1), 67-80.

Islam, K.K., Fujiwara, T., Tani, M., \& Sato, N. (2014). Marketing of agroforestry products in Bangladesh: a value chain analysis. Ameican Jaumal of Agiailture and Forestry, 2(4), 135-145. 
Mukson, Santosa, S.I., Setiyawan, H., \& Suryanto, B. (2005). Analisis efisiensi pemasaran telur ayam ras di K abupaten Kendal Jawa Tengah. Seminar Nasional TAkndog PtemakandanV te niner(pp. 755-762). Semarang: Fakultas Peternakan Universitas D iponegoro.

Premono, B.T. \& Lestari, S. (2012). Analisis pemasaran kayu bawang di Provinsi Bengkulu. Pro sidingSeminarHasil PenditianBalai PenditianKe hutanan Palenbang Pduang dan Tantangan Pe ngembanganUsahaKayuRakyat', Palembang 23 O ktober 2012 (pp. 47-59). Bogor: Pusat Penelitian dan Pengembangan Peningkatan Pro-duktivitas Hutan.
Rosmawati, H. (2011). Analisis efisiensi pemasaran pisang produksi petani di Kecamatan Lengkit Kabupaten Ogan Komering Ulu. AgrondiS, 3(5), 1-9.

Setiorini, F. (2008). Analisis fisiens pemasaran ikan mas di Keeamatan Pagdaran, Kabupaten Tangget ms, Proind Lampung (Skripsi). Program Stu-di Manajemen Bisnis dan Ekonomi Perikanan - Kelautan, Fakultas Perikanan dan Ilmu Ke-lautan, Institut Pertanian Bogor, Bogor. 